Creating Productive and Upcoming Sport Education Profesional Hmzanwadi University

Vol.3, No.2, Desember 2020, Hal. 103-109

e-ISSN 2614-8781

\title{
PENGARUH LATIHAN PASSING 5, 10, 15 METER TERHADAP KETEPATAN PASSING SEPAKBOLA
}

\author{
Shandy Pieter Pelamonia ${ }^{1}$, Andre Putra Hutapea ${ }^{2}$ \\ Email : $\underline{\text { shandypieter.or@gmail.com }}{ }_{\text {, andreputra13526@gmail.com }}^{2}$ \\ 1,2 Pendidikan Jasmani, Fakultas Pedagogi dan Psikologi, Universitas PGRI Adi Buana Surabaya
}

\begin{abstract}
Abstrak
Penelitian ini dilatar belakangi karena tim SSB Putra Jambangan memiliki Kemampuan passing tidak bagus dan tidak terarah. Rumusan dalam penelitian ini yaitu adakah pengaruh latihan Passing 5, 10, 15 meter terhadap ketepatan passing sepakbola pada siswa SSB Putra Jambangan Surabaya. Penelitian ini bertujuan untuk mengetahui pengaruh latihan passing 5, 10, 15 meter terhadap kemampuan ketepatan passing bola pada permainan sepakbola SSB Putra Jambangan Surabaya. Subjek penelitian adalah siswa SSB Putra Jambangan Surabaya. Jenis penelitian ini adalah eksperimen dengan desain "The One Group Pretest, Posttest Design". Instrument yang digunakan yaitu menendang bola dan memantulkan ke dinding sebagai sasaran selama 39 detik. Analisis data menggunakan uji t dengan taraf signifikan 5\%. Hasil penelitian menunjukkan bahwa ada pengaruh yang signifikan pada Latihan passing 5, 10, 15 meter terhadap ketepatan passing sepakbola pada siswa SSB Putra Jambangan Surabaya, dengan nilai $t_{\text {hitung }} 19,186>$ besat $t_{\text {tabel }} 2,074$, dan nilai signifikansi $0,000<0,05$.
\end{abstract}

Kata Kunci: Passing 5,10,15 Meter, Ketepatan Passing

\begin{abstract}
This research was motivated because the Putra Jambangan SSB team had poor and un-directed passing abilities. the formulation in this research is whether there is an effect of Passing 5,10,15 meter training on the accuracy of football passing on SSB Putra Jambangan Surabaya students. this study aims to determine the effect of passing exercises 5,10,15 meters on the ability of passing ball accuracy in the soccer game Putra Jambangan Surabaya Surabaya. The subjects were SSB Putra Jambangan Surabaya students. This type of research is an experiment with the design "The One Group Pretest, Posttest Design". The instrument used was kicking the ball and reflecting on the wall as a target for 39 seconds. Date analysis using $t$ test with a significance level of 5\%. the results showed that there was a significant influence on the passing exercise 5,10,15 meters on the passing accuracy of football on the SSB Putra Jambangan Surabaya students, with a tcount of 19.186> the magnitude of a table of 2.074, and a significance value of $0.000<0.05$.
\end{abstract}

Keywords: Passing 5, 10, 15 Meters, Passing Accuracy

\section{A. Pendahuluan}

Sepak bola merupakan salah satu cabang olahraga populer di dunia umumnya. perkembangan sepakbola di Indonesia di tandai dengan berdirinya persatuan sepakbola seluruh Indonesia (PSSI). Berdirinya PSSI semakin mendapat sambutan yang positif dari masyarakat 
sehingga menjadi pelopor berdirinya klub-klub sepakbola baik dari tingkat daerah maupun nasional,selanjut nya sepakbola menunjukkan sisi positifnya dalam membangun mental dan fisik masyarakat dan juga jadi ajang pembuktian jatidiri serta media kompetensi yang sehat. Untuk dapat bermain sepakbola dengan baik pemain dibekali dengan teknik dasar yang baik. Pemain yang memiliki teknik dasar yang baik, maka pemain tersebut cenderung dapat bermain dengan baik pula. Selain teknik dasar yang baik yang harus dimiliki oleh pemain sepakbola juga harus memiliki kemampuan fisik yang baik untuk menunjang keterampilan bermain sepakbola. Dalam permainan sepakbola di butuhkan kondisi fisik yang baik untuk menunjang keterampilan bermain sepakbola seperti kecepatan, kekuatan, daya tahan. Sukadianto (2011:235). Kemapuan fisik dibedakan menjadi 2 yaitu kemampuan fisik umum dan kemapuan fisik khusus, kemampuan fisik umum meliputi kekuatan, daya tahan, kecepatan, kelincahan, dan kelentukan, sedangkan kemampuan fisik khusus meliputi stamina, power, reaksi, koordinasi, ketepatan, dan keseimbangan.

Semua komponen kondisi fisik di atas harus dipaduhkan sedimikian rupa agar dapat menjadi pemain sepakbola yang tidak hanya baik secara fisik namun juga teknik, taktik, dan mental sehingga dapat menjadi pemain yang berkualitas dan berprestasi. Pemain sepakbola memiliki keterampilan yang kompleks dan bersifat terbuka ketermpilan sepakbola meliputi : menendang bola, mengiring bola, menyundul bola, merampas bola, melempar bola, menangkap bola, dan mengoper bola. Salah satu teknik dasar yang sangat penting dalam sepakbola adalah mengoper bola. Maka dari itu, setiap pemain sepakbola harus menguasai teknik mengoper bola dengan benar. Mengoper bola sering juga di sebut dengan passing. Passing adalah memindahkan bola dari satu pemain ke pemain lainnya. Untuk melakukan passing, bagian tubuh yang tepat adalah kaki. Ada beberapa cara dalam teknik passing dengan menggunakan kaki yaitu 1. Passing dengan bagian dalam kaki. 2. Passing dengan bagian samping luar kaki. 3. Passing denga kurakura kaki. Tim SSB Putra Jambangan mamiliki kemampuan passing yang jelek, ketika beberapa pemain mengoper bola selalu tidak tepat kepada temannya, sehingga bola lebih mudah diambil oleh lawan. Untuk itu seorang pelatih perlu memilih metode atau bentuk latihan mana yang akan digunakan atau diterapkan dalam passing yang baik. Ada berbagai macam metode latihan untuk dapat meningkatkan kemampuan passing pada pemain SSB Putra jambangan. Salah satu nya adalah dengan latihan passing kearah yang sudah ditentukan dengan jarak yang bervariasi.

\section{B. Metode}

Penelitian ini termasuk quasi experiment, desain yang digunakan dalam penelitian ini adalah "The One Group Pretest-Posttest Design" atau tidak adanya group kontrol (Sukardi, 2009:18). Metode eksperimen dengan sampel tidak terpisah maksdunya penelitiannya memiliki satu kelompok saja, yang di ukur dua kali, pengukuran pertama (pretest) dilakukan sebelum subjek diberiperlakuan, kemudian perlakuan (treatment), yang akhirnya di tutup dengan pengukuran kedua (posttest). Penelitian ini melakukan tes sebanyak 2 kali yaitu: sebelum dan sesudah perlakuan. Perbedaan antara pretest dan posttest ini di asumsikan merupakan efek dari treatment atau eksperimen. Sehingga hasil dari perlakuan diharapkan dapat di ketahui lebih akurat, karena terdapat perbandingan antara keadaan sebelum dan sesudah diberiperlakuan. Perlakuan yang diberikan dalam penelitian ini adalah latihan passing 5,10,15 meter. Populasi dalam penelitian ini adalah siswa SSB Putra Jambangan Surabaya yang berjumlah 23 orang. Penelitian ini menggunakan teknik total sampling yaitu sebanya 23 siswa SSB Putra Jambangan Surabaya. Metode eksperimen dengan sampel tidak terpisah maksdunya penelitiannya memiliki satu kelompok saja, yang di ukur dua kali, pengukuran pertama (pretest) dilakukan sebelum 
subjek diberi perlakuan, kemudian perlakuan (treatment), yang akhirnya di tutup dengan pengukuran kedua (posttest). Ketepatan diukur dengan Jhonson Soccer Tes, yang pada umumnya digunakan untuk melakukan tes umum sepakbola.

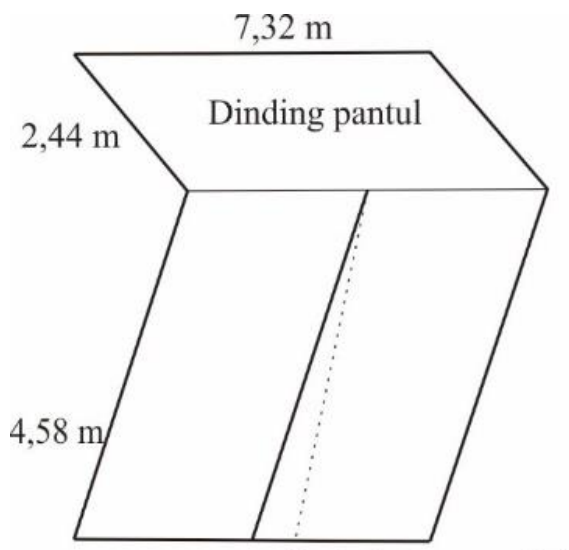

Garis batas peserta tes

Gambar 1. Lapangan Johnson Soccer Test

Analisis data yang digunakan meliputi analisis statistik deskriptif, uji normalitas. Analisis deskriptif akan menggambarkan secara umum hasil penelitian berupa skor yang didapat selama proses penelitian. Pengujian hipotesis menggunakan uji paired sample t test untuk mengetahui apakah ada pengaruh yang signifikan dari pengaruh perlakuan penelitian.

\section{Hasil dan Pembahasan}

Hasil

Pengukuran ketepatan passing dengan teknik passing 5,10,15 meter SSB Putra Jambangan Surabaya dilakukan sebanyak 2 (dua) kali, yaitu pretest (sebelum) dan posttest (sesudah).

Tabel 1. hasil pengukuran ketepatan passing

\begin{tabular}{cccccc} 
& \multirow{2}{*}{ NO } & NAMA & \multicolumn{4}{c}{$\begin{array}{c}\text { Hasil pretest dan posttest } \text { dari kemampuan } \\
\text { Ketepatan passing sepakbola }\end{array}$} \\
\cline { 3 - 6 } & SISWA & PRETEST & POSTTEST & D & $\mathrm{D}^{2}$ \\
\hline 1 & $\mathrm{Ra}$ & 23 & 28 & 5 & 25 \\
2 & $\mathrm{Ga}$ & 21 & 25 & 4 & 16 \\
3 & $\mathrm{Ta}$ & 21 & 25 & 4 & 16 \\
4 & $\mathrm{M} . \mathrm{a}$ & 25 & 30 & 5 & 25 \\
5 & $\mathrm{Hu}$ & 20 & 24 & 4 & 16 \\
6 & $\mathrm{Bi}$ & 25 & 27 & 2 & 4 \\
7 & $\mathrm{Vi}$ & 18 & 23 & 5 & 25 \\
8 & $\mathrm{Di}$ & 19 & 24 & 5 & 25 \\
9 & $\mathrm{Al}$ & 20 & 24 & 4 & 16 \\
10 & $\mathrm{Haf}$ & 26 & 32 & 6 & 36 \\
11 & $\mathrm{Na}$ & 22 & 25 & 3 & 9 \\
12 & $\mathrm{Alf}$ & 20 & 24 & 4 & 16 \\
13 & $\mathrm{Dio}$ & 23 & 28 & 5 & 25 \\
14 & $\mathrm{Ma}$ & 25 & 29 & 4 & 16 \\
15 & Fav & 18 & 23 & 5 & 25
\end{tabular}

Journal Pendidikan Jasmani Kesehatan \& Rekreasi (PORKES) |105 
Creating Productive and Upcoming Sport Education Profesional Hmzanwadi University Vol.3, No.2, Desember 2020, Hal. 103-109

e-ISSN 2614-8781

\begin{tabular}{cccccc}
16 & $\mathrm{An}$ & 23 & 26 & 3 & 9 \\
17 & $\mathrm{M} . \mathrm{d}$ & 20 & 24 & 4 & 16 \\
18 & $\mathrm{Ab}$ & 19 & 23 & 4 & 16 \\
19 & $\mathrm{Ba}$ & 22 & 25 & 3 & 9 \\
20 & $\mathrm{Pu}$ & 21 & 23 & 2 & 4 \\
21 & $\mathrm{Yo}$ & 24 & 28 & 4 & 16 \\
22 & $\mathrm{Kh}$ & 20 & 23 & 3 & 9 \\
23 & $\mathrm{Daf}$ & 23 & 27 & 4 & 16 \\
\hline \multicolumn{2}{c}{} & 498 & 590 & 92 & 390
\end{tabular}

Tabel diatas mengambarkan skor dari variabel ketepatan yang diperoleh dari hasil penelitian. Besar perubahan didapatkan dari nilai delta yang dibandingkan dengan nilai pretest. Data tersebut mengambarkan perubahan hasil ketepatan oleh kelompok dalam penelitian.

Tabel 2. hasil pretest dan posttest kemampuan ketepatan passing

\begin{tabular}{|c|c|c|c|c|c|c|}
\hline \multicolumn{3}{|c|}{ Frekuensi pretest dan posttest } & \multicolumn{2}{|c|}{ Pretest } & \multicolumn{2}{|c|}{ posstest } \\
\hline No & $\begin{array}{l}\text { Skor } \\
\text { akhir }\end{array}$ & Kategori & $\mathrm{F}$ & $\%$ & $\mathrm{~F}$ & $\%$ \\
\hline 1 & $>42$ & $\begin{array}{c}\text { BAIK } \\
\text { SEKALI }\end{array}$ & 0 & $0 \%$ & 0 & $0 \%$ \\
\hline 2 & $37-41$ & BAIK & 0 & $0 \%$ & 0 & $0 \%$ \\
\hline 3 & $31-36$ & SEDANG & 0 & $0 \%$ & 1 & $4,34 \%$ \\
\hline 4 & $25-30$ & KURANG & 3 & $13,04 \%$ & 12 & $52,16 \%$ \\
\hline 5 & $<24$ & $\begin{array}{c}\text { KURANG } \\
\text { SEKALI }\end{array}$ & 20 & $86,96 \%$ & 10 & $43,50 \%$ \\
\hline
\end{tabular}

Untuk menganalisis apakah ada signifikan dan apakah ada perbedaan yang signifikan antara nilai pretest dan posttest, maka untuk menghitung penulis menggunakan rumus uji-t, sebelumnya peneliti menghitung nilai rata-rata perbedaan atau selisih dari pretest dan posttest.

1. Mean (rata-rata)

$$
\text { a. } \begin{aligned}
\text { M pretest } & =\frac{\Sigma}{\mathrm{N}} \\
& =\frac{498}{23} \\
& =21,65
\end{aligned}
$$

b. $\quad M$ posttest $=\frac{\Sigma}{\mathrm{N}}$

$$
\begin{aligned}
& =\frac{590}{23} \\
& =25,65
\end{aligned}
$$

Berdasarkan dari perhitungan di atas di peroleh nilai dari hasil pretest sebelum di berikan perlakuan dengan model pemberian materi menggunakan latihan passing 5,10, 15 meter pada 
siswa SSB Putra Jambangan Surabaya berjumlah 498 dengan mean 21,65 dan jumlah nilai posttest sesudah di berikan perlakuan dengan menggunakan latihan passing 5,10,15 meter pada siswa SSB Kecamatan Jambangan berjumlah 590 dengan mean 25,65 dengan hasil tersebut dapat di ketahui perbedaan jumlah skor pretest $=498$ dan posttest $=590$.

2. Uji Hipotesis

a. Perhitungan $t_{\text {hitung }}$ sebagai berikut :

Uji $t_{\text {hitung }}$ (t-test) adalah teknik statistic yang dipergunakan untuk menguji signifikasi perbedaan dua buah mean yang berasal dari dua buah distribusi.

$$
\begin{aligned}
\mathrm{t} & =\frac{\Sigma \mathrm{D}}{\sqrt{\frac{N \Sigma \mathrm{D}^{2}-(\Sigma \mathrm{D})^{2}}{\mathrm{~N}-1}}} \\
& =\frac{92}{\sqrt{\frac{23.390-(92)^{2}}{23-1}}} \\
& =\frac{92}{\sqrt{\frac{8.970-8.464}{22}}} \\
& =\frac{92}{\sqrt{\frac{506}{22}}} \\
& =\frac{92}{\sqrt{23}} \\
& =19,186
\end{aligned}
$$

b. Perhitungan $t_{\text {tabel }}$ sebagai berikut :

$$
\begin{aligned}
\mathrm{t}_{\text {tabel }} & =\mathrm{n}-1 \\
& =23-1 \\
& =22
\end{aligned}
$$

Tabel 3. Hasil Perhitungan $t_{\text {tabel }}$

\begin{tabular}{cccc}
$\mathbf{N}$ & T.hitung & T.tabel & Keterangan \\
\hline $\mathbf{2 3}$ & 19,186 & 2,074 & Signifikan \\
\hline
\end{tabular}


Jadi dari hasil analisis di atas, maka terdapat pengaruh yang signifikan pada hasil latihan passing 5,10,15 meter terhadap ketepatan passing sepakbola pada siswa SSB Putra Jambangan Surabaya.

Pembahasan

Deskripsi data menunjukkan bahwa kelompok perlakuan mengalami peningkatan ketepatan passing. Hal ini terbukti dari hasil perhitungan atau analisis data tersebut diatas di peroleh perhitungan sebesar $t_{\text {hitung }} 19,186$ sedangkan pada $t_{\text {tabel }}$ dan $\mathrm{df}=\mathrm{n}-1=23-1=22$ dengan taraf signifikan 5\% adalah sebesar 2,074 atau $\left(t_{\text {hitung }}>t_{\text {tabel }}\right)$, sehingga dapat $t_{\text {hitung }}$ lebih besar dari $t_{\text {tabel }}$ maka hasil analisis tersebut menunjukkan bahwa ada pengaruh latihan passing 5,10,15 Meter terhadap ketepatan passing sepakbola pada siswa SSB Putra Jambangan Surabaya. Dengan demikian hipotesis kerja (Ha) yang menyatakan ada pengaruh pelatihan passing 5,10,15 Meter terhadap ketepatan passing sepakbola pada siswa SSB Putra Jambangan Surabaya diterima. Jadi dapat di simpulkan bahwa "ada pengaruh" yang signifikan pada latihan passing 5,10,15 Meter terhadap ketepatan passing sepakbola pada siswa SSB Putra Jambangan Surabaya.

\section{Simpulan}

Ada pengaruh latihan passing 5,10,15 Meter terhadap ketepatan passing sepakbola pada siswa SSB Putra Jambangan Surabaya, hal ini dapat di buktikan dengan di terimanya hipotesis yang pertama dengan hasil $t_{\text {hitung }}>$ besar $t_{\text {tabel }}$ yang artinya hipotesis di terima. Hal ini sesuai dan didukung dari penelitian terdahulu yang relevan yang meneliti tentang perbedaan latihan passing bawah bervariasi dan latihan passing bawah lurus berhadapan terhadap ketepatan passing siswa SSB Garuda Muda KU 10-12 Tahun. Penelitian ini dilakukan oleh Abdul Haqqiadnan. (2013), dan memiliki hasil latihan passing bawah bervariasi terhadap ketepatan passing siswa SSB Garuda Muda kelompok usia 10-12 Tahun, dengan Nilai t hitung 12.25 > t table 2.14, dan nilai signifikan $0.000<0.05$, kenaikan persentase sebesar $72.06 \%$, pengaruh latihan passing bawah lurus berhadapan terhadap ketepatan passing siswa SSB Garuda Muda kelompok usia 10-12 Tahun. Dengan niali t hitung $7.790>\mathrm{t}$ table 2.14, dan nilai signifikan $0.000<0.05$. kenaikan persentase sebesar $42.03 \%$, serta Latihan passing bawah bervariasi lebih baik dari pada latihan passing bawah lurius berhadapan terhadapn ketepatan passing siswa SSB Garuda Muda kelompok usia 10-12 Tahun, dengan t hitung 3.660 $>$ t table $=2.05$ dan sig. $0.001<0.05$.

\section{Daftar Pustaka}

Abdul Haqqiadnan. (2013). Pengaruh Latihan Passing Berpasangan Terhadap Ketepatan Passing Pada Permain Sepakbola SSB Petrogres Gresik. Skripsi. Surabaya: FKIP ADIBUANA SURABAYA.

Annas, B., Dinata, K., \& Daniyantara, D. (2018). Hubungan Imt Dengan Kelincahan Menggiring Bola Pada Siswa Putera Ekstrakulikuler Sepak Bola Siswa Sman 1 Aikmel Tahun 2017. Jurnal Porkes, 1(1), 07-13.

Ambarukmi,D.A.Dkk. 2007 Pelatihan Pelatih Fisik Level I, Deputi Bidang Peningkatan Prestasi dan IPTEK Olahraga. Kemenpora

Arikunto Suharsimi, 2006. Prosedur Penelitian . Jakarta: PT Rineka

Bompa, T., \& Buzzichelli, C. (2015). Periodization training for sports, 3e. Human kinetics

Daniyantara, D., Suryadi, L. E., \& Nuhayadi, S. A. (2020). Perbandingan Tingkat Keterampilan Dribbling Dengan Metode Latihan Slalom Dribbling Dan Tepukan Dribbling. Jurnal Porkes, 3(1), 49-52. 
Creating Productive and Upcoming Sport Education Profesional Hmzanwadi University

Vol.3, No.2, Desember 2020, Hal. 103-109

e-ISSN 2614-8781

Djoko Pekik Irianto. (2002). Dasar Pelatihan. Yogyakarta: FIK UNY

Hulfian, L. (2020). Latihan Kelincahan Boomerang Run Dapat Meningkatkan Keterampilan Menggiring Bola Dalam Permainan Futsal. Jurnal Porkes, 3(1), 9-14.

Jovanovic, M., Sporis, G., Omrcen, D., \& Fiorentini, F. (2011). Effects of speed, agility, quickness training method on power performance in elite soccer players. The Journal of Strength \& Conditioning Research, 25(5), 1285-1292.

Jusran, S., \& Hariadi, H. (2020). Kontribusi Kecepatan, Kelincahan Dan Keseimbangan Dengan Kemampuan Menggirng Dalam Permainan Futsal. Jurnal Porkes, 3(1), 37-43.

Lhaksana, J. (2011). Taktik \& Strategi futsal modern. Be Champion

Luxbacher, Joseph. (2011). Sepakbola Edisi Dua. Rajagrafindo Persada.

Maksum, A. (2012). Metode Penelitian Dalam Olahraga. Surabaya. Unesa University Press

Muhammad. (2012). Pengaruh Latihan Passing Satu Dua Sentuhan Terhadap Kemampuan Passing Di Sekolah Sepakbola Kelud Putra Sukodono Sidoarjo.Surabaya: FKIP ADIBUANA SURABAYA.

Mardhika, R. (2020). Standing Jump Over Barrier Mempengaruhi Keterampilan Menendang Bola (Shooting) Cabang Olahraga Sepakbola. Jurnal Porkes, 2(2), 50-57.

Quddus, A., Dinata, K., \& Daniyantara, D. (2018). Pengaruh Variasi Latihan Terhadap Peningkatan Keterampilan Bermain Sepak Bola Pada Club Putra Baja Fc Tahun 2017. Jurnal Porkes, 1(1), 21-26.

Saputra, S. Y., \& Suarti, N. K. A. (2019). Pengaruh Gaya Mengajar Resiprokal Terhadap Hasil Menendang Bola Dalam Permainan Sepak Bola pada Siswa Putra Kelas VII SMPN 1 Gerung Lombok Barat. Jurnal Porkes, 2(1), 06-12.

Sporiš, G., Milanović, Z., Trajković, N., \& Joksimović, A. (2011). Correlation between speed, agility and quickness (SAQ) in elite young soccer players. Acta Kinesiologica, 5(2), 3641.

Sugiyono. 2010. Statistika Untuk Penelitian. Bandung : Alfabeta.

Sugiyono. 2011 Metode Penelitian Pendidikan (Pendekatan kualitatif, kuantitatif, dan R \&D. Bandung :Alfabeta.

Suharjana. 2007. Latihan Beban. Yogyakarta : FIK UNY.

Sukadiyanto. 2005. Pengantar Teori dan Melatih Fisik. Yogyakarta: FIK UNY.

Wora, D., Adiatmika, I P., Fufu, O., Adiputra, N., Muliarta, M., \& Adiarta, P. G. (2017). Pelatihan Zig-Zag Run Lebih Efektif Meningkatkan Kelincahan Menggiring Bola Dari Pada Pelatihan Shutle Run Dalam Permainan Futsal. 